\title{
IMAGE
}

\section{Insights image for exploration of potential biochemical markers for persistence of patent ductus arteriosus in preterm infants at 22-27 weeks' gestation}

Karl Wilhelm Olsson ${ }^{1}$, Anders Larsson ${ }^{2}$, Anders Jonzon ${ }^{1}$ and Richard Sindelar ${ }^{1}$

Pediatric Research (2019) 86:413; https://doi.org/10.1038/s41390-019-0458-9

Illustration of the studied biomarkers proposed to indicate a persistent patent ductus arteriosus (PDA), their suggested relationship to a PDA, and the organs and tissues that potentially produces them.

\section{REFERENCE}

1. Olsson, K. W., Larsson, A., Jonzon, A., Sindelar R. Exploration of potential biochemical markers for persistence of patent ductus arteriosus in preterm infants at 22-27 weeks' gestation. Pediatr Res. (2018). https://doi.org/10.1038/s41390-0180182-x [Epub ahead of print]

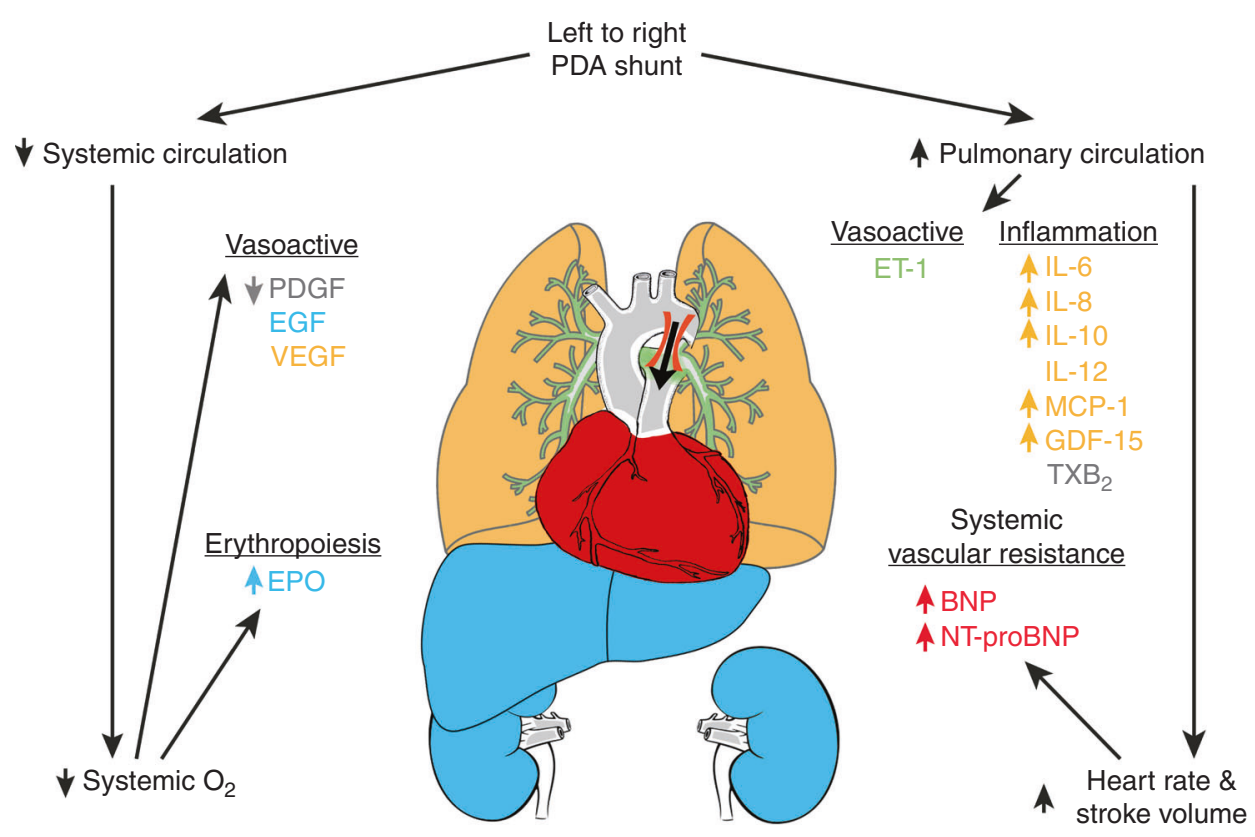

\footnotetext{
${ }^{1}$ Department of Women's and Children's Health, Uppsala University, Uppsala, Sweden and ²Department of Medical Sciences, Uppsala University, Uppsala, Sweden
} Correspondence: Karl Wilhelm Olsson (karl_wilhelm.olsson@kbh.uu.se) 